\title{
ANALYZING FLOW ENERGY POTENTIAL OF THE BOSPHORUS STRAIT
}

\author{
Mehmet Özturk, Yildiz Technical University, meozturk@hotmail.com. \\ Cihan Sahin, Yildiz Technical University, cisahin@inm.yildiz.edu.tr. \\ Yalcin Yuksel, Yildiz Technical University, yalcinyksl@gmail.com.
}

\begin{abstract}
INTRODUCTION
Ocean currents represent a potentially notable, currently untapped, reservoir of energy. The regions with strong current velocities such as narrow straits connecting two water bodies exhibit high current energy (power) potential especially where the water depths are relatively shallow (EECA, 2009).

The Bosphorus, given in Figure 1, connecting the Black Sea to the Sea of Marmara is a typical narrow sea strait that generally exhibits a two-layered flow pattern: the upper layer current flows south towards the Sea of Marmara while the underlying current flows in opposite direction towards the Black Sea (Yüksel et al., 2008). The predominant mechanisms for the upper and lower layer flows are the higher water level of the Black Sea and the denser water of the Sea of Marmara, respectively.
\end{abstract}

\section{THE AIM OF STUDY}

The present study aims at revealing annual current energy potential of the Bosphorus by means of three dimensional numerical model results. The numerical model was calibrated with one-year current measurements at three different depths. After determining the most energetic regions in the strait (Figure 2), the cross-sectional variations were also analyzed at two sites.

\section{RESULTS}

The results show that there is a significant variability in kinetic energy of the flow both in space and time. Due to the stable water level increase at the Black Sea entrance, induced by increasing river run-off into the Black Sea during the late spring and summer, the current velocities of the strait reach about $2 \mathrm{~m} / \mathrm{s}$ during peak periods. However, the highest kinetic energies are obtained in the case of stable water level increase at the north entrance combined with severe meteorological conditions (i.e. strong northern winds). In contrast, the strong southerly winds may block the southward upper layer flow and push it back in the opposite direction mainly during winter. This blockage causes nearly zero velocity (or kinetic energy) conditions up to $30 \%$ of the year even in the energetic sections.

Due to the south sill, which is located near the southern exit of the strait, the southernmost part of the strait is the most productive in terms of the kinetic energy potential. In horizontal plane, due to the meandering shape of the geometry, the kinetic energy of the strait is higher at the outer bank for the upper layer flow.

The results show that the complex geometry (both horizontally and vertically) of the strait combined with highly variable hydrological and meteorological conditions of the adjacent seas, the Marmara Sea and the Black Sea, result in a considerable fluctuation on the kinetic energy potential ranging from nearly zero to 50 gigawatt. The kinetic energy flux maintains peak values between May and July, which is attributed to the fact that the Bosphorus has stable hydrological and meteorological conditions supported by abundance of river inflow (Danube, Dinyeper and Dinyester from the north of the Black Sea) into the Black Sea during these months.

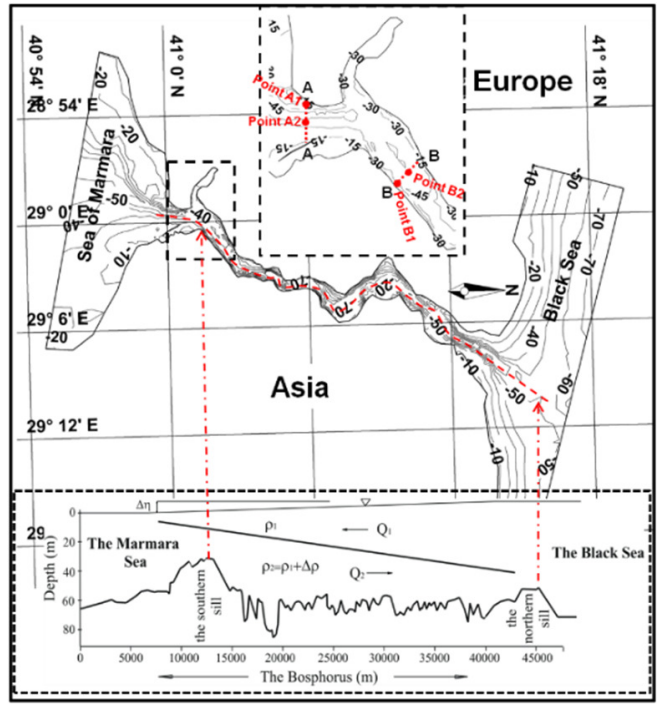

Figure 1 - The plan and cross-sectional view of the Bosphorus

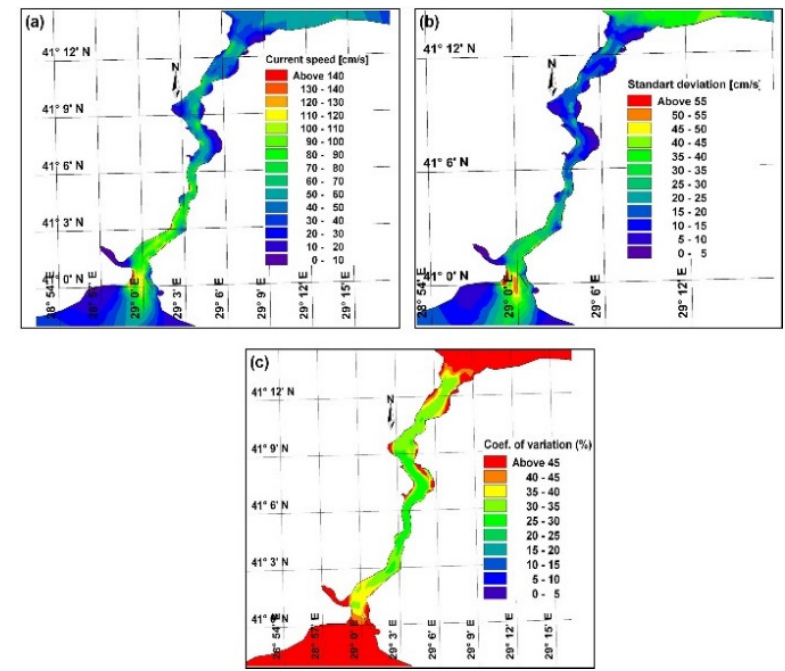

Figure 2 - Spatial variations of (a) annual mean current speed, (b) standard deviation and (c) the coefficient of variation of the current

\section{REFERENCES}

Energy Efficiency and Conservation Authority (EECA) (2009), Development of Marine Energy in New Zealand, Technical Report. Accessed at http://www.eeca.govt.nz/node/1331.

Yüksel, Ayat, Öztürk, Aydoğan, Güler, Çevik and Yalçıner (2003): Responses of the stratified flows to their driving conditions a field study, OCEAN ENG ,vol. 35, pp. 13041321. 